Japan. J. Med. Sci. Biol., 21, 103-113, 1968

\title{
SOME ASPECTS OF ANTIMYCOBACTERIAL PROPERTIES OF MOUSE LYSOSOMAL COMPONENTS
}

\author{
KOOMI KANAI \\ Department of Tuberculosis, National Institute of Health, Tokyo
}

(Received : September 28th, 1967)

\begin{abstract}
SUMMARY : Lysosomal components were obtained as a Triton-lysate of the lung and spleen granular fractions of mice infected with virulent tubercle bacilli or BCG. Incubation of tubercle bacilli with the components resulted in that the bacilli gained the lysosomal acid phosphatase activity, whereas the phosphatase activity specific for the bacilli decreased with simultaneous reduction of viability. Lysosomal components were subjected to gel-filtration on Sephadex G-100 and G-200 column with the hope of separation of antimycobacterial and phosphatase activities. A fraction was obtained which had a mycobactericidal property and a property of inhibiting bacillary acid phosphatase activity. On the other hand, a separate fraction showed the affinity to the bacilli giving them the additional phosphatase activity at the lower $\mathrm{pH}$ range, but exerting no bactericidal action. These results reveal one aspect of the lysosome-bacillus interaction in tuberculous infection. The results also support the idea that the $\mathrm{pH}$ pattern of phosphatase activity shown by "in vivo grown tubercle bacilli" is the combined results of inhibition of the bacillus-specific enzymatic activity and coating of such bacilli with lysosomal acid phosphatase.
\end{abstract}

\section{INTRODUCTION}

Being encouraged by the initial observation that "in vivo grown tubercle bacilli" isolated from the infected mouse lungs were coated with host acid phosphatase and the same enzymatic activity proper to the bacilli was inhibited (Kanai, 1967a), the author proceeded to a study on lysosome-bacillus interaction in experimental mouse tuberculosis. Acid phosphatase is the most representative lysosomal enzyme of phagocytic cells and it is generally admitted that the contents of lysosomes are discharged into the bacillus-containing phagocytic vacuole (Hirsch, 1965). With this information in mind, an attempt was made to establish an in vitro model for such subcellular environment. Lysosomal compoments were released by Triton X-100 treatment from the granular fraction of the $0.25 \mathrm{M}$ sucrose homogenate of the spleen and lungs. Incubation at $37 \mathrm{C}$ of in vitro grown tubercle bacilli with the lysosomal components resulted in coating of the bacilli with lysosomal acid phosphatase and reduction of their enzymatic activity (Kanai, $1967 \mathrm{~b}$ ). In other words, the in vitro grown bacilli acquired the properties of the in vivo bacilli during the stay in such an experimental model environment.

During the course of these experiments, the author noticed that tubercle bacilli exposed to lysosomal components lost their viability in some instances. This chance 
observation led the author to a fractionation study of lysosomal components with the hope of separation of antimycobacterial and phosphatase activities.

\section{MATERIALS AND METHODS}

Experimental animals: Mice were used throughout the present study. They were of the commercially available dd strain, weighing around $20 \mathrm{~g}$ on the average. They were housed, 10 per box, on wood shavings in metal boxes with wire grid tops, and fed with pellet diet and water.

Microorganisms: Mycobacterium tuberculosis (H37Rv and H37Ra), Mycobacterium bovis (BCG), and Mycobacterium smegmatis were the microorganisms employed. They have been maintained on Sauton synthetic liquid medium. Bacillary suspensions for infection, vaccination and in vitro experiments were prepared from pellicle growth on that medium. The growth was harvested on a funnel and then dried being pressed between layered folds of absorbent filter paper. A weighed portion of thus prepared bacillary mass was put into a round flask of $300 \mathrm{ml}$ capacity containing 60 beads of 7 $\mathrm{mm}$ diameter. Finely dispersed bacillary suspension was prepared by rotating the flask manually with occasional adding of suspending medium. The kind of medium was usually distilled water but sometimes some other kind depending upon the experimental purpose. The amount of medium was adjusted so as to obtain the desired concentrarations (mg per $\mathrm{ml}$ ) of the bacilli. Such a procedure as above was followed using chilled materials and equipments to prevent bacillary aggulutination.

Infection and vaccination of mice: Infection with $\mathrm{H} 37 \mathrm{Rv}$ tubercle bacilli was conducted intravenously at the tail vein. Size of the inoculum was $1 \mathrm{mg}$ to produce fatal infection and $0.1 \mathrm{mg}$ or less to produce nonfatal persistent infection. Vaccination with BCG was conducted in the same way with $1 \mathrm{mg}$ inoculum.

Enumeration of viable units of bacillary suspension: Enumeration of viable units of bacillary suspension was made by making serial ten-fold dilutions of the original with distilled water and subsequently by inoculating $0.1 \mathrm{ml}$ of selected dilutions onto glycerol egg slants of the Ogawa type. For colony counting, incubation for 3 weeks at $37 \mathrm{C}$ was satisfactory.

Preparation of cell fractions: The lungs and spleens were removed from a large number of mice vaccinated or infected 2 to 3 weeks previously and stored at $-20 \mathrm{C}$. Those infected organs were used for the reason that they gave a better yield of lysosomal components than noninfected organs. The pooled organs were homogenized by a Waring blender set at a high speed using a stainless steel container of 1 litre capacity. A suspending medium for $40 \mathrm{~g}$ of the organs, $50 \mathrm{ml}$ of a $0.35 \mathrm{M}$ sucrose solution containing $\mathrm{CaCl}_{2}$ in $3.3 \mathrm{mM}$, was put into the container before starting agitation. After 20 min agitation, $200 \mathrm{ml}$ of a $0.25 \mathrm{M}$ sucrose solution containing $\mathrm{CaCl}_{2}$ in $3 \mathrm{mM}$ was added to the homogenate and stirred again for a while. In order to control the rise in temperature, a metal cylinder case was fixed around the container, in which ice water was filled. The homogenate was then passed through 3 sheets of gauze. The filtrate was centrifuged at $1,000 \mathrm{~g}$ for $20 \mathrm{~min}$. The resulting sediment was discarbed and the supernatant was recentrifuged at $15,000 \mathrm{~g}$ for $20 \mathrm{~min}$. The resulting supernatant containing microsomes and cell sap was preserved without further fractionation. The sediment containing mitochondria and lysosomes was not separated further and referred to as "lysosomal" fraction. It was resuspended into $100 \mathrm{ml}$ of $0.25 \mathrm{M}$ sucrose solution containing $\mathrm{MgCl}_{2}$ in $5 \mathrm{mM}$, and centrifuged again in the same 
condition as before. The resulting pellet was the washed lysosomal fraction.

Fractionation of lysosomal components: The washed lysosomal fraction obtained from $30 \mathrm{~g}$ organs was resuspended into $40 \mathrm{ml}$ of $0.25 \mathrm{M}$ sucrose solution containing $\mathrm{MgCl}_{2}$ in $5 \mathrm{mM}$ and also a nonionic detergent, Triton X-100, in $0.1 \%$. The suspension was left to stand in an ice box for $10 \mathrm{~min}$ and then centrifuged at $15,000 \mathrm{~g}$ for $20 \mathrm{~min}$. The resulting supernatant was referred to as the Triton-released lysosomal components, and the test for acid phosphatase activity revealed that $90 \%$ of the total activity of the original suspension moved to the supernatant. This supernatant was subjected to fractionation by gel-filtration on Sephadex G-100 or G-200. Before loading, samples of lysosomal components were concentrated to a suitable protein concentration by evaporation with a flash-evaporator and dialysed against $0.1 \mathrm{M}$ acetate buffer $\mathrm{pH} 5.6$. For gel filtration, Sephadex gel was packed into a column $(33 \times 2.8 \mathrm{~cm}$ or $25 \times 2 \mathrm{~cm}$ ) and equilibrated with the buffer overnight. Elution was performed using thd same buffer, starting from 1 to $2 \mathrm{hr}$ after sample was layered on the column, at a temperature of $4 \mathrm{C}$ with a flow rate of $25 \mathrm{~g}$ per hr. Eluates were collected in 5 or $4 \mathrm{~g}$ amount. Assay for protein amount and acid phosphatase activity was done of each eluate. Protein amount was expressed as optical density at $280 \mathrm{~m} \mu$ measured with a Beckman spectrophotometer or as $\mathrm{mg}$ tyrosine per $\mathrm{ml}$ measured by Folin test. Acid phosphatase activity was expressed as $\mu \mathrm{M}$ p-nitrophenol liberated from p-nitrophenyl phosphate per $30 \mathrm{~min}$. per $\mathrm{ml}$ eluate at $37 \mathrm{C}$ and $\mathrm{pH} 3.5$.

Assay of acid phosphatase activity: Activity was determined using 0.5 per cent p-nitrophenyl phosphate as substrate and $0.1 \mathrm{M}$ acetate buffers ranging in $\mathrm{pH}$ from 3.5 to 6.2 , and also maleic acid buffer of $\mathrm{pH} 6.5$. The reaction mixture consisted of 0.8 $\mathrm{ml}$ of buffer, $0.1 \mathrm{ml}$ of substrate solution, $0.1 \mathrm{ml}$ of $100 \mu \mathrm{M}$ EDTA, and $0.1 \mathrm{ml}$ of enzyme sample. The amount of released p-nitrophenol was determined by Coleman spectrophotometer set at $420 \mathrm{~m} \mu$ after alkalinization of the mixture with $2 \mathrm{ml}$ of $0.5 \mathrm{M}$ $\mathrm{NaOH}$. Blank tube was added with $\mathrm{NaOH}$ at zero time. The activity was expressed as $\mu$ moles of $\mathrm{p}$-nitrophenol released in a given time at $40 \mathrm{C}$ by specified amount of test samples each time. When the bacilli were enzyme sample, reading was made after removing them by centrifugation.

Incubation of the bacilli with lysosomal components or their fractions : Four hundred mg of the bacilli grown on Sauton synthetic medium were suspended in $10 \mathrm{ml}$ of lysosomal components or their fractions separated by gel filtration. The mixture was added with $\mathrm{CaCl}_{2}$ in $3 \mathrm{mM}$ and $\mathrm{MgCl}_{2}$ in $5 \mathrm{mM}$ and placed in an incubator at $37 \mathrm{C}$ for a given time. After this treatment the bacilli were collected and washed with distilled water by centrifugation at $1,000 \mathrm{~g}$. The pellet of the bacilli was inserted between layered folds of absorbent filter paper to remove the moisture and weighed. A $50 \mathrm{mg}$ per $\mathrm{ml}$ bacillary suspension was prepared from this material using one drop of $0.5 \%$ Tween 80 solution and distilled water as suspending medium. This suspension was used for the test of acid phosphatase activity in the amount of $0.1 \mathrm{ml}$ in each reaction tube. And the remaining portion was used for enumeration of viable counts by serial ten-fold dilution and plating on Ogawa's glycerol egg media.

In some particular case, a simplified method was employed to see only the bactericidal activity of test samples. A $10^{-2} \mathrm{mg}$ per $\mathrm{ml}$ bacillary suspension was prepared using the test sample as suspending medium. After incubation at $37 \mathrm{C}$ for a given time, the suspension was directly diluted and plated onto glycerol egg media. This method was used mainly for a preliminary survey. 


\section{RESULTS}

\section{Effects of Incubation with Mouse Cell Fractions on Acid Phosphatase Activity and Viability of Tubercle Bacilli}

Lysosomal components and the supernatant fraction (the microsome and cell sap fraction) were obtained from the mouse spleens infected with virulent tubercle bacilli (H37Rv) 4 weeks previously. The protein concentrations were found to be 600 and $2,023 \mu \mathrm{g}$ expressed as tyrosine per $\mathrm{ml}$ respectively. An incubation experiment was conducted using these samples against $400 \mathrm{mg}$ BCG at $37 \mathrm{C}$ for $3 \mathrm{hr}$. This type of experiment was repeated using the materials from the spleens and lungs of the similarly infected mice. The incubation was done using $\mathrm{H} 37 \mathrm{Rv}$ tubercle bacilli as test microorganisms at $37 \mathrm{C}$ for $18 \mathrm{hr}$. Incubation effects on bacillary viability and phosphatase activity in both experiments are shown in Table 1. In Exp. 1, bactericidal activity was found only in lysosomal components, viable counts being reduced from $18 \times 10^{6}$ down to $15 \times 10^{4}$. The enzymatic activity at $\mathrm{pH} 6.5$ decreased to $93.1 \%$ of the control value, and the activity at $\mathrm{pH} 3.5$ increased from 0.005 to 0.052 . The bacilli incubated with the supernatant fraction gained a marked phosphatase activity at $\mathrm{pH} 3.5$, but there was no significant change in viability. The activity at $\mathrm{pH} 6.5$ decreased only by $13.5 \%$. Thus, antibacterial effects were revealed by lysosomal components but not by the supernatant even at the higher protein concentration.

Table 1. Effects of incubation with mouse lysosomal components or with the supernatant fraction on viability and acid phosphatase activity of tubercle bacilli

\begin{tabular}{|c|c|c|c|c|c|c|}
\hline \multirow{3}{*}{ Exp. No. } & \multirow{3}{*}{ Organ } & \multirow{3}{*}{ Fraction } & \multirow{3}{*}{$\begin{array}{c}\text { Folin value } \\
\text { ( } \begin{array}{c}\text { g tyrosine! } \\
\mathrm{ml})\end{array}\end{array}$} & \multicolumn{3}{|c|}{$\begin{array}{c}\text { Incubation (at } 37 \mathrm{C}) \text { effects } \\
\text { on bacilli* }\end{array}$} \\
\hline & & & & Viable & $\begin{array}{l}\text { Acid phosp } \\
\text { activity* }\end{array}$ & $\begin{array}{l}\text { hatase } \\
* \text { at }\end{array}$ \\
\hline & & & & $\begin{array}{l}\text { counts } \\
\text { per mg }\end{array}$ & $\begin{array}{l}\mathrm{pH} 6.5 \\
\text { (\% decrease) }\end{array}$ & $\mathrm{pH} 3.5$ \\
\hline \multirow{3}{*}{1} & \multirow{2}{*}{ Spleen } & $\int$ Lysosomal components & 600 & $15 \times 10^{4}$ & $0.018(93.1)$ & 0.052 \\
\hline & & Supernatant & 2,191 & $11 \times 10^{6}$ & $0.225(13.5)$ & 0.036 \\
\hline & \multicolumn{3}{|c|}{$\begin{array}{c}0.25 \mathrm{M} \text { sucrose containing (Control) } \\
\text { Triton X-100 }\end{array}$} & $18 \times 10^{5}$ & 0.26 & 0.005 \\
\hline \multirow{8}{*}{2} & \multirow{4}{*}{ Spleen } & Lysosomal components & 916 & $17 \times 10^{4}$ & $0.04(85.7)$ & 0.41 \\
\hline & & $1: 10$ dilution & 91.6 & $8 \times 10^{5}$ & $0.086(69.3)$ & 0.019 \\
\hline & & $\int$ Supernatant & 4,500 & $18 \times 10^{5}$ & $0.12(57.1)$ & 0.48 \\
\hline & & $\{1: 3$ dilution & 1,500 & $21 \times 10^{6}$ & $0.29(0)$ & 0.012 \\
\hline & \multirow{4}{*}{ Lung } & $\int$ Lysosomal components & 691 & $26 \times 10^{4}$ & $0.028(90.0)$ & 0.18 \\
\hline & & $\{1: 10$ dilution & 69.1 & $9 \times 10^{5}$ & $0.45(73.2)$ & 0.007 \\
\hline & & ( Supernatant & 3,500 & $13 \times 10^{6}$ & $0.26(7.1)$ & 0.145 \\
\hline & & $1: 3$ dilution & 1,166 & $15 \times 10^{5}$ & $0.28(0)$ & 0.008 \\
\hline & \multicolumn{3}{|c|}{$0.25 \mathrm{M}$ sucrose (Control) } & $16 \times 10^{6}$ & 0.28 & 0.003 \\
\hline
\end{tabular}

* BCG was incubated for $3 \mathrm{hr}$ in Exp. 1 and H37Rv was incubated for $18 \mathrm{hr}$ in Exp. 2.

** $\mu \mathrm{M}$ p-nitrophenol released from p-nitrophenyl phosphate by $5 \mathrm{mg}$ bacilli at $40 \mathrm{C}$ for $90 \mathrm{~min}$. 
In Exp. 2, a 1:10 dilution of lysosomal components and a $1: 3$ dilution of the supernatant were also examined. The bactericidal activity of lysosomal components was remarkable in reducing viable counts from $16 \times 10^{6}$ to $17 \times 10^{4}$ or to $26 \times 10^{4}$ Even by the 1.10 dilutions, viable counts decreased down to $8 \times 10^{5}$ or to $9 \times 10^{5}$. These changes of viable counts were accompanied by a reduction of phosphatase activity at $\mathrm{pH} 6.5$ by as much as 70 to $90 \%$ of the control value.

Incubation with the lung supernatant fraction gave the bacilli the elevated enzymatic activity at $\mathrm{pH} 3.5$, but there occurred no significant change in viability and phosphatase activity at $\mathrm{pH}$ 6.5. However, the undiluted spleen supernatant of the higher protein concentration $(4,500 \mu \mathrm{g}$ as tyrosine per $\mathrm{ml}$ ) had some bactericidal activity at $\mathrm{pH}$ 6.5 by $57.1 \%$. These results appear to indicate that an antimycobacterial factor or factors are concentrated in the lysosomes, and that the loss of bacillary viability is more related to inhibition of the enzymatic activity at $\mathrm{pH} 6.5$ than to coating of the bacilli with lysosomal acid phosphatase as revealed by the elevated activity at $\mathrm{pH} 3.5$.

\section{Fractionation of Lysosomal Components by Gel Filtration on Sephadex G-100}

Three hundred and twenty $\mathrm{ml}$ of Triton-released lysosomal components was obtained from $390 \mathrm{~g}$ of the combined spleens and lungs of BCG-vaccinated mice. It was then concentrated by a flash-evaporator to $80 \mathrm{ml}, 20 \mathrm{ml}$ of which was dialysed against $0.1 \mathrm{M}$ acetate buffer of $\mathrm{pH} 5.6$ and loaded on a Sephadex column of 33 by $2.8 \mathrm{~cm}$. Eluates were collected in $5 \mathrm{~g}$ amounts with a flow rate of $25 \mathrm{~g}$ pea hr. Each eluate was examined for acid phosphatase activity and protein amount. The results are presented in Fig. 1. As shown here, two protein peaks appeared, the first being steep and high

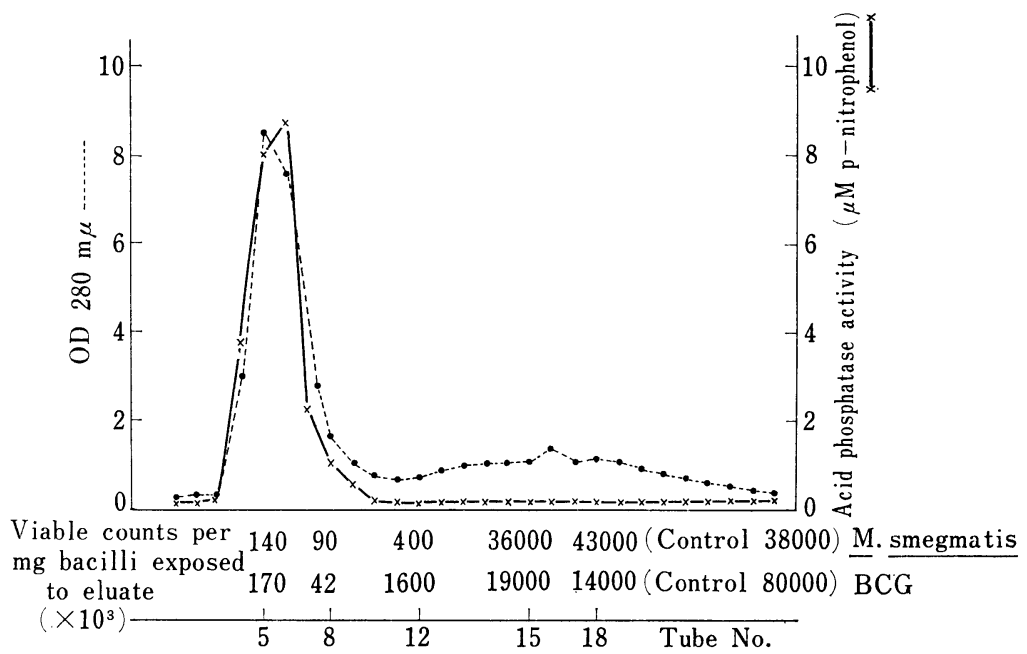

Fig. 1. Fractionation of lysosomal components by gel filtration on Sephadex G-100, with reference to acid phosphatase activity and mycobactericidal activity.

and the second being broad and low. Acid phosphatase activity was associated with the first, and the second peak had no activity. Then, antibacterial activity of Tubes No. $5,8,12,15$ and 18 was surveyed by the simplified method with BCG and $M$. smegmatis as test microorganisms. Exposure time was $16 \mathrm{hr}$ at $37 \mathrm{C}$ for the former 
and $4 \mathrm{hr}$ for the latter. Bactericidal activity was detected in No. 5, 8 and 12 tubes as revealed by a marked reduction of viable counts. In view of this preliminary observation, an incubation experiment was performed with BCG. The eluates of Tubes No. 5, 6, 7, 8, 9 and 10 were combined. Ten $\mathrm{ml}$ of the combined eluate was incubated with $\mathrm{BCG}$ for $18 \mathrm{hr}$ at $37 \mathrm{C}$. The details of the experimental procedure were the same as described in the preceding section. The results are demonstrated in Fig. 2. The figure indicates that the treated BCG organisms acquired the enzymatic activity at the $\mathrm{pH}$ range of from 3.5 to 5.0 , and their original activity at $\mathrm{pH} 6.5$ was reduced. Reduction of viable counts was remarkable, changing from $21 \times 10^{7}$ to $28 \times$ $10^{3}$. Thus, the main protein peak was found to be associated with both the antimycobacterial activity and phosphatase activity. However, the observation that the eluate No. 12 was negative for the enzymatic activity but positive for bactericidal activity prompted us to a further attempt to separate the two properties.

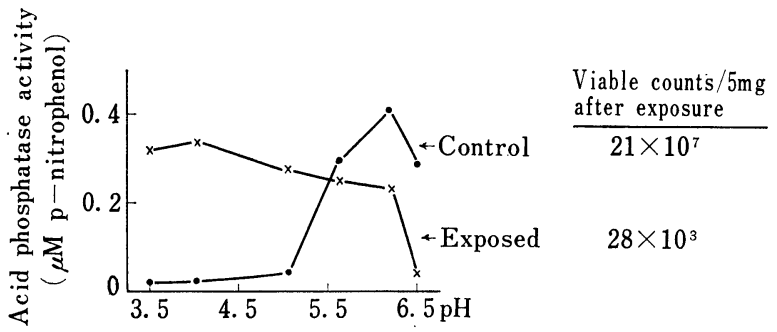

Fig. 2. Changes of acid phosphatase activity and viability of BCG after exposure to a Sephadex G-100 fraction (Combined eluates No. 5 to 10 in Fig. 1).

One hundred and fifty $\mathrm{ml}$ of lysosomal components was prepared from $165 \mathrm{~g}$ of the mouse lungs stimulated by BCG 2 weeks previously. The protein concentration was $217 \mu \mathrm{g}$ as tyrosine per $\mathrm{ml}$ and the total amount was $32.3 \mathrm{mg}$, and it was concentrated into $32 \mathrm{ml}$ by a flash-evaporator. On the other hand, $130 \mathrm{ml}$ of lysosomal components was prepared from $136 \mathrm{~g}$ of the BCG-stimulated mouse spleens. The protein concentration was $450 \mu \mathrm{g}$ per $\mathrm{ml}$ and the total amount was $59 \mathrm{mg}$. The material was concentrated into $23 \mathrm{ml}$ in the same way as above. Acid phosphatase activity at $\mathrm{pH} 3.5$ was 0.35 ( $\mu \mathrm{Mp}$-nitrophenol liberated at $40 \mathrm{C}$ for $30 \mathrm{~min}$ ) per $\mathrm{mg}$ protein for the lung lysosomal components and 1.0 per $\mathrm{mg}$ protein for the spleen lysosomal components. The concentrated materials were loaded on Sephadex G-100 column of $33 \times 2.8 \mathrm{~cm}$. Eluates were collected in $5 \mathrm{~g}$ amounts, each of which being assayed for the enzymatic activity and protein amount. The results are presented in Fig. 3. The elution pattern in both cases was essentially the same as the previous experience. However, the interval phase between the two protein peaks was extended and a small peak of phosphatase activity was detected therein. Then, an incubation experiment was conducted using Fraction A (combined eluates No. 16 to 20) of the lung lysosomal components and Fraction B (combined eluates No. 14 to 18) of the spleen lysosomal components against $\mathrm{H} 37 \mathrm{Rv}$ tubercle bacilli at $37 \mathrm{C}$ for $18 \mathrm{hr}$. These fractions were selected for this incubation experiment because of their low phosphatase activity and of their location in the elution pattern which correspond to or near No. 12 tube in the previous experiment. Changes of acid phosphatase activity and viability in the bacilli exposed to Fraction $\mathrm{A}$ and $\mathrm{B}$ are shown in Fig. 4. Being treated by Fraction A, the enzymatic 


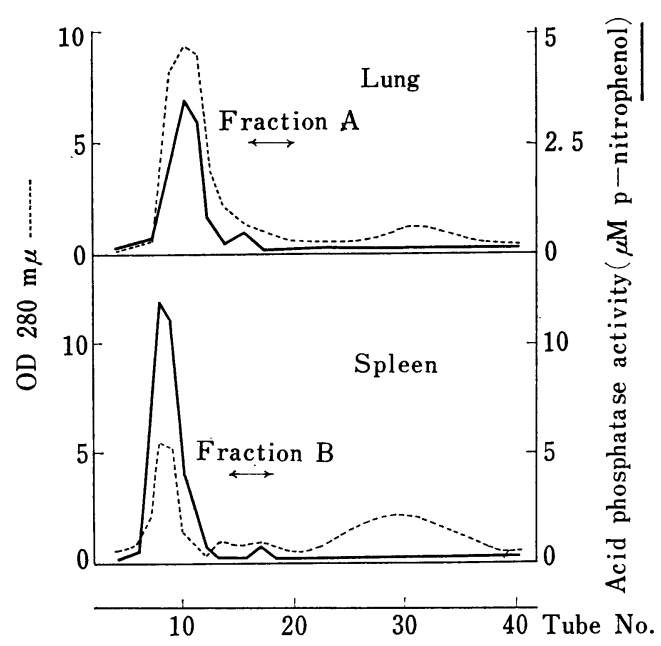

Fig. 3. Fractionation of lysosomal components by gel filtration on Sephadex G-100.

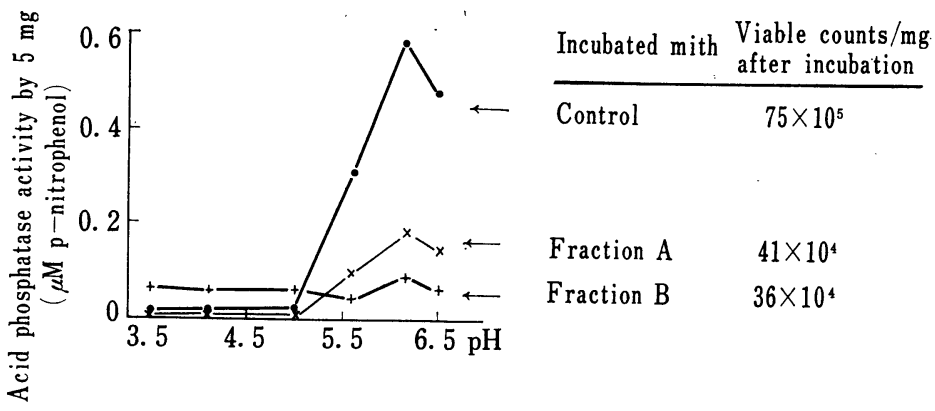

Fig. 4. Changes of acid phosphatase activity and viability in H37Rv bacilli after exposure to Sephadex G-100 fractions A and B in Fig. 3.

activity of the bacilli decreased remarkably without altering the general pattern of $\mathrm{pH}$ activity curve. The viability was also reduced from $75 \times 10^{5}$ to $41 \times 10^{4}$. In the bacilli exposed to Fraction B, decrease of the enzymatic activity was more pronounced, though a slight but definite elevation of the activity at $\mathrm{pH}$ range of from 3.5 to 5.0 was found. The viability was again reduced down to $36 \times 10^{4}$. These results strongly suggest the possibility that the antimycobacterial factor or factors will be distinct from lysosomal acid phosphatase.

\section{Fractionation of Lysosomal Components by Gel Filtration of Sephadex G-20O}

One hundred and seventy $\mathrm{ml}$ of Triton-released lysosomal components was obtained from $160 \mathrm{~g}$ of the spleens of BCG-vaccinated mice. This sample contained $23 \mathrm{mg}$ protein. It was concentrated to $25 \mathrm{ml}$ by a flash-evaporator and then dialysed against $0.1 \mathrm{M}$ acetate buffer, $\mathrm{pH}$ 5.6. The dialysed material was loaded on a Sephadex G-200 column of $33 \times 2.8 \mathrm{~cm}$, which had been equilibrated with the buffer overnight. Eluates obtained with the same buffer were collected in $5 \mathrm{~g}$ amounts with a flow rate of $25 \mathrm{~g}$ per $2 \mathrm{hr}$. Each tube was assayed for the enzymatic activity and protein amount. The 


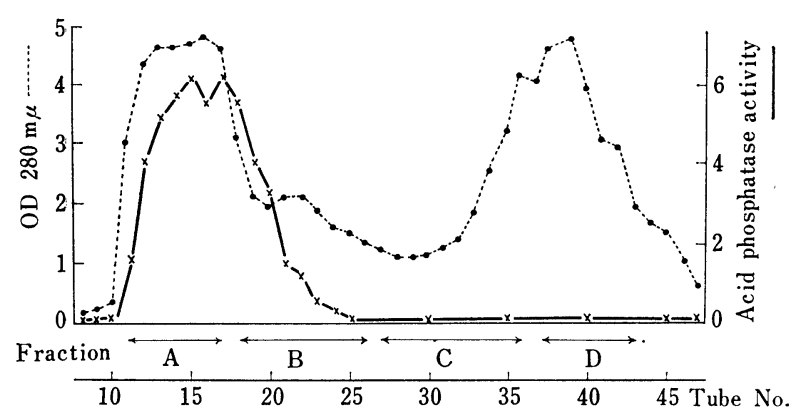

Fig. 5. Fractionation of spleen lysosomal components by gel filtration on Sephadex G-200.

results are presented in Fig. 5. The elution pattern was similar to that of Sephadex G-100 as seen before through the first protein peak was broader and followed by a small accessory peak. Acid phosphatase activity was accociated with the first protein peak with a slight shift of the peak.

Eluates Nor 11 to 17 were pooled to make Fraction A, and eluates No. 18 to 26 were pooled to make Fraction B. Eluates No. 27 to 36 were pooled and designated as Fraction $\mathrm{C}$ and dialysed against $0.01 \mathrm{M}$ acetate buffer of $\mathrm{pH} 5.6$ and concentrated to $35 \mathrm{ml}$. Fluates No. 37 to 43 were combined to form Fraction D which was then treated in the same way as Fraction $\mathrm{C}$ making the total amount $28 \mathrm{ml}$. Fractions A and B were then subjected to rechromatography on Sephadex G-200 of a $20 \times 2 \mathrm{~cm}$ column after being concentrated to $20 \mathrm{ml}$ and dialysed against $0.01 \mathrm{M}$ acetate buffer of $\mathrm{pH} 5.6$ for $3 \mathrm{hr}$. Elution was carried out using the same buffer and eluates were collected in $4 \mathrm{~g}$ amounts. The elution patterns were as shown in Figs. 6 and 7 . As seen in Fig. 6, Fraction A was separated into the first protein peak which was high and steep and the second protein peak which was very low and broad. Acid phosphatase activity was exclusively associated with the first protein peak. The eluates No. 5 to 8 were then combined and termed Fraction RA. This was concentrated to $23 \mathrm{ml}$. On rechromatography Fraction $\mathrm{B}$ turned into a single round protein peak with a little

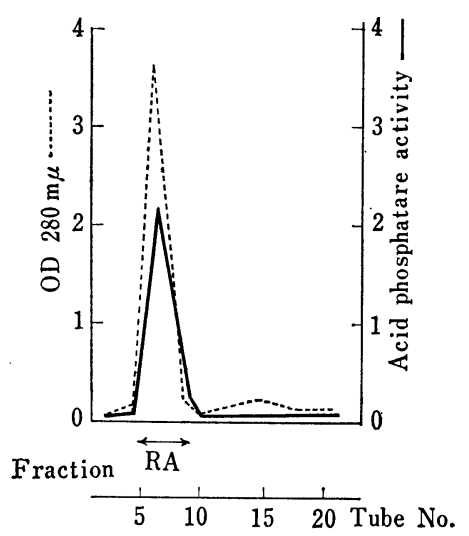

Fig. 6. Rechromatography on Sephadex G-200 of Fraction A in Fig. 5.

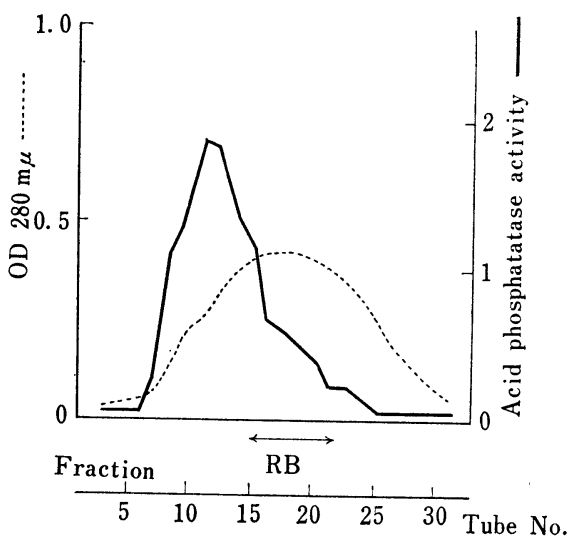

Fig. 7. Rechromatography on Sephadex G-200 of Fraction B in Fig. 5. 
shoulder in the left side. The major part of the enzymatic activity was associated with the first half of the peak, the maximum intensity corresponding to the shoulder. Eluates No. 15 to 22 were combined and concentrated to $14 \mathrm{ml}$ (Fraction RB).

Folin tests were carried out of Fraction RA, RB, C and D to evaluate their protein concentration, the value obtained being found to be $65,66,95$ and $15 \mu \mathrm{g}$ tyrosine per $\mathrm{ml}$, respectively. An incubation experiment was conducted using each $\mathrm{ml}$ of these four fractions and, as a control, acetate buffer $(0.01 \mathrm{M})$ against H37Ra tubercle bacilli at $37 \mathrm{C}$ for $16 \mathrm{hr}$. Incubation effects on the bacilli are shown in Fig. 8 . The bacilli treated with Fraction RA gained the new phosphatase activity at $\mathrm{pH}$ range from 3.5 to 5.0 , and their original activity at $\mathrm{pH} 5.0$ to 6.5 was elevated or kept on the same level. However, there was no significant change in their viability. On the other hand, the bacilli exposed to Fraction $\mathrm{C}$ showed the greatly lowered phosphatase activity keeping the original pattern of $\mathrm{pH}$ activity curve. This decrease of enzymatic activity was accompanied by a marked reduction of viability from $12 \times 10^{6}$ to $15 \times 10^{3}$. Fraction $\mathrm{C}$ is, therefore, considered as the antimycobacterial fraction. Treatment with Fraction $\mathrm{B}$ exerted the effect which is intermediate between those of the above two kinds of fractions; a moderate reduction of the activity at $\mathrm{pH} 5.6$ to 6.5 and some elevation of the activity at $\mathrm{pH} 3.5$ to 5.0. Reduction of viability to some extent was also observed in this case. These changes indicated that Fraction $\mathrm{B}$ was a mixture of lysosomal phosphatase and antimycobacterial factors. Meanwhile, Fraction D was almost inactive in any of these respects.

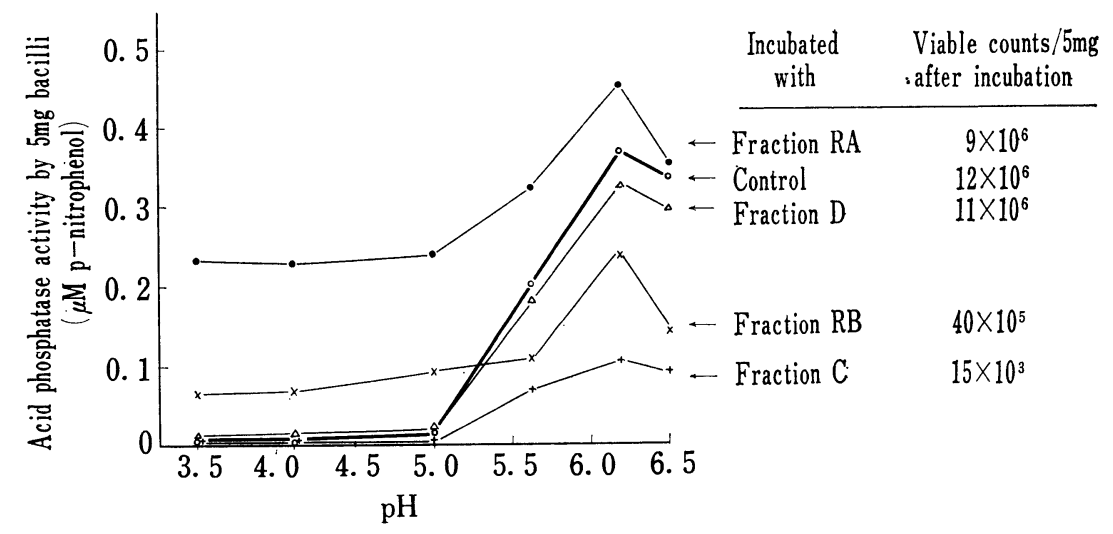

Fig. 8. Changes of acid phosphatase activity and viability of H37Ra tubercle bacilli after incubation with Sephadex G-200 fractions RA, RB, $\mathrm{C}$ and $\mathrm{D}$ in Fig. 5, 6 and 7.

\section{DISCUSSION}

The present study demonstrated that Triton-released lysosomal components have a fraction which reduces viability of tubercle bacilli under some conditions of $\mathrm{pH}$, temperature and concentration. In addition, the fraction has a property of reducing acid phosphatase activity of the bacilli. However, a question still remains whether these two antibacterial effects are caused by a single factor or are the simultaneous occurrence of independent effects due to two different factors contained in the fraction. On the other hand, the findings in this fractionation study can explain reasonably the 
nature of the particular $\mathrm{pH}$ activity curve of acid phosphatase as revealed by " in vivo grown tubercle bacilli" and also by the in vitro bacilli treated with lysosomal components (Kanai, $1967 \mathrm{a}, \mathrm{b}$ ). Tubercle bacilli grown in vitro have $\mathrm{pH}$-activity curve with a single steep peak between 5.6 and 6.5 and the negligible activity between 5.0 to 3.5. The inhibitor of lysosomal components reduces the activity keeping this pattern as it is. Meanwhile, the $\mathrm{pH}$ activity curve of lysosomal acid phosphatase has a very broad peak between 3.19 and 6.2 and a steep slop down to 6.5. Therefore, when the bacilli, whose acid phosphatase activity has been inhibited as above, become coated with the lysosomal enzyme, then they acquire or regain the activity at $\mathrm{pH} 3.19$ to 6.2 , but the reduced activity at $\mathrm{pH} 6.5$ remains low. This might be also a possible situation of lysosome-bacillus interaction as established within phagocytic vacuole associated with degranulation.

On the other hand, the mechanism of mycobacterial action by lysosomal components and its association with tuberculous immunity are unknown as yet, and these problems are now under investigation in this laboratory.

Cohn and Hirsch (1960) have ever demonstrated the presence of acid hydrolases and antibacterial activity in association with the granules (lysosomes) of rabbit polymorphonuclear leucocytes. The antibacterial principle was named "phagocytin" by them. This observation was then confirmed and extended by Spitznagel and Chi (1963) and Zeya and Spitznagel (1963). More recently, Zeya and Spitznagel (1966 a, b) finally succeeded in demonstrating that the antibacterial factor is a cationic protein rich in arginine and distinct from lysosomal enzymes such as lysozyme, acid ribonuclease, and acid deoxyribonuclease. The proteins manifested antibacterial activities against a variety of gram-negative and gram-positive microorganisms, including Candida albicans; for example reduction of viable counts, suppression of oxygen uptake by bacterial cells, and damage of the permeability barriers of the cells. However, their papers stated nothing about the effects on mycobacteria and the relation with lysosomal acid phosphatase. In this regard, a question is raised about whether their cationic proteins from polymorphonuclear leucocyte lysosomes are identical with the fraction found in the present study which was mycobactericidal and inhibited the bacillary acid phosphatase activity. Answer will be made only after a more detailed investigation is made of the biological and biochemical properties of the fraction. On the other hand, phagocytin is interpreted by Zeya and Spitznagel ( $1966 \mathrm{~b})$ to be a heterologous mixture of enzymes and their lysosomal cationic proteins.

Another leucocytic factor which has ever been reported as antimycobacterial is lysozyme (Myrvik, Leake and Fariss, 1961). It was also known to be localized in cytoplasmic granules and discharged into the phagocytic vacuole (Leake and Myrvik, 1964). Oshima, Myrvik and Leake (1961) demonstrated that lysozyme is a dominant tuberculastatic factor in extracts of granulomatous lungs. In view of these informations, the presence of lysozyme in our mycobactericidal fraction should be examined.

Finally, the report of Artman and Bekierkunst (1961) will be worthy of attention that in vivo grown tubercle bacilli are coated with host NADase. NADase is known to be a particulate (microsomal) enzyme, but the bactericidal activity is not yet proved thereof. 


\section{REFERENCES}

ARtMAn, M. AND BekieRkunst, A. (1961): Studies on Mycobacterium tuberculosis H37Rv grown in vivo. Am. Rev. Resp. Diseases, 83, 100-106.

COHN, Z. A. AND HIRSCH, J. G. (1960): The isolation and properties of specific cytoplasmic granules of rabbit polymorphonuclear leucocytes. J. Exptl. Med., 112, 983-1009.

HiRSCH, J. G. (1965) : Phagocytosis. Ann. Rev. Microbiol., 19, 339-350.

KANAl, K. (1967 a) : Detection of host-originated acid phosphatase on the surface of " in vivo grown tubercle bacilli". Jap. J. Med. Sci. Biol., 20, 73-90.

KANAI, K. (1967 b): Affinity of lysosomal acid phosphatase to the surface of the tubercle bacillus. Jap. J. Med. Sci. Biol., 20, 401-411.

LEAKe, E. S. AND MYRviK, Q. N. (1964): Differential release of lysozyme and acid phosphatase from subcellular granules of normal rabbit alveolar macrophages. Brit. J. Exptl. Pathol., 45, 384-392.

MYRViK, Q. N., LEAKE, E. S. AND FARISs, B. (1961): Lysozyme content of alveolar and peritoneal macrophages from the rabbit. J. Immunol., 86, 133-136.

Oshima, S., Myrvik, Q. N. AND Leake, E. (1961): The demonstration of lysozyme as a dominant tuberculostatic factor in extracts of granulomatous lungs. Brit. J. Exptl. Pathol., 42, 138-144.

SpItzNagel, J. K. AND CHI, H. K. (1963) : Cationic proteins and antibacterial properties of infected tissues and leucocytes. Am. J. Pathol., 43, 692-711.

Zeya, H. I. AND SpItzNAGEL, J. K. (1963): Antibacterial and enzymic basic proteins from leucocyte lysosomes: Separation and identification. Science, 142, 1085-1087.

ZEYA, H. I AND SPITZNAGEL, J. K. (1966 a) : Cationic proteins of polymorphonuclear leucocyte lysosomes. I. Resolution of antibacterial and enzymatic activities. J. Bacteriol., 91, 750-754.

Zeya, H. I. AND SpitzNAGEL, J. K. (1966 b) : Cationic proteins of polymorphonuclear leucocyte lysosomes. II. Composition, properties, and mechanism of antibacterial action. J. Bacteriol., 91, 755-762. 